20

\title{
Влияние длительного перорального введения золотых наночастиц различного размера на печень, селезенку и лимфатические узлы лабораторных крыс и их потомства*
}

\author{
(C) С.С. Пахомий ${ }^{1}$, А.Б. Бучарская ${ }^{1, \uparrow, ~ Г . Н . ~ М а с л я к о в а ~}{ }^{1}$, О.В. Злобина ${ }^{1}$, И.О. Бугаева ${ }^{1}$, \\ Н.А. Наволокин ${ }^{1}$, Д.А. Мудрак ${ }^{1}$, Б.Н. Хлебцов ${ }^{2}$, В.А. Богатырев ${ }^{2}$, Н.Г. Хлебцов ${ }^{2}$ \\ ${ }^{1}$ Саратовский государственный медицинский университет им. В.И. Разумовского, \\ 410012 Саратов, Россия \\ ${ }^{2}$ Институт биохимии и фризиологии растений и микроорганизмов РАН, \\ 410049 Саратов, Россия \\ ฯe-mail: allaalla_72@mail.ru
}

Поступила в редакцию 15.12.2018 г.

В окончательной редакции 01.01.2019 г.

Принята к публикации 09.01.2019 г.

\begin{abstract}
Изучено влияние длительного перорального введения золотых наночастиц различного размера на строение печени, селезенки и лимфатических узлов половозрелых лабораторных крыс и их потомства. Морфометрическое исследование проводили с помощью системы анализа цифровых изображений Микровизора медицинского $\mu$ Vizo-103. Выявление конгломератов золотых наночастиц в тканях осуществляли с помощью метода микроскопии темного поля. Установлено, что золотые наночастицы размерами 2 и $50 \mathrm{~nm}$ вызывают наиболее выраженные морфологические изменения в органах, что свидетельствует о размерзависимом характере их воздействия. В печени в группе введения золотых наночастиц размером $50 \mathrm{~nm}$ наблюдались выраженная дистрофия гепатоцитов и активация моноцитарно-макрофагальной системы. В селезенке и лимфатических узлах происходила активация процессов пролиферации и дифференцировки иммунокомпетентных клеток и макрофагов. Пероральное введение золотых наночастиц во время беременности самкам сопровождалось увеличением числа гепатоцитов с некробиотическими изменениями и повышением количества непаренхиматозных элементов в печени у потомства, наиболее выраженное в группах с введением золотых наночастиц размерами 2 и $50 \mathrm{~nm}$.
\end{abstract}

DOI: 10.21883/OS.2019.06.47770.19-19

\section{Введение}

В последнее время активно развивается новое направление в молекулярной диагностике и терапии злокачественных новообразований - тераностика [1-3]. Тераностика предполагает разработку веществ с терапевтическими и диагностическими свойствами, соединенными в одном средстве. Применение нанотехнологий считается перспективным для решения задач тераностики. Размер наночастиц позволяет им преодолевать биологические тканевые барьеры и проникать внутрь клетки. Среди наноразмерных материалов в качестве потенциальных агентов для тераностики особое место занимают золотые наночастицы (ЗНЧ) [4]. Антиоксидантные свойства, биосовместимость и способность к плазмонному резонансу определяют перспективность применения ЗНЧ $[5,6]$. Они могут использоваться в качестве носителей для таргетной доставки лекарственных веществ, генетического материала, антигенов [4], как флуорес-

\footnotetext{
* The 22nd Annual Conference Saratov Fall Meeting 2018 (SFM'18): VI International Symposium, „Optics and Biophotonics“ and XXII International School for Junior Scientists and Students on Optics, Laser Physics \& Biophotonics, September 24-29, 2018, Saratov, Russia. https://www.sgu.ru/structure/fiz/saratov-fall-meeting/previousconferences/saratov-fall-meeting-2018
}

центные метки в томографии участков опухолевого роста, контрастирующие агенты в магнитно-резонансной томографии [7] и для оптической визуализации структур клеток [8].

До начала клинического применения ЗНЧ необходима тщательная оценка их потенциальной токсичности, а также способности преодолевать гистогематические барьеры. Большинство исследований посвящено оценке токсического действия наночастиц при их внутривенном введении у половозрелых животных, в то же время альтернативные пути введения, а также воздействие наночастиц на потомство при пренатальном и перинатальном воздействии изучены недостаточно. В опубликованных нами ранее работах было установлено, что длительное пероральное введение ЗНЧ половозрелым животным может приводить к дистрофическим и некротическим изменениям в паренхиматозных органах и сопровождаться активацией моноцитарно-макрофагальной системы $[9,10]$. За последние годы опубликованы исследования о проницаемости плацентарного барьера для различных видов наночастиц $[11,12]$. В исследовании ex vivo на плаценте человека было установлено, что ЗНЧ размерами $10-30 \mathrm{~nm}$ не проникают через гематоплацентарный барьер [13,14]. До настоящего времени недостаточно изученными остаются вопросы влияния 
длительного перорального введения ЗНЧ у беременных животных и во время лактации на морфологическое строение внутренних органов потомства.

Цель исследования - оценить влияние длительного перорального введения ЗНЧ размерами 2, 15 и $50 \mathrm{~nm}$ на морфологическое строение печени, селезенки и лимфатических узлов половозрелых лабораторных крыс и их потомства.

\section{Материалы и методы}

Экспериментальное исследование проводили на 48 самцах и 40 самках белых беспородных крыс с массой тела $250 \pm 20 \mathrm{~g}$. Все исследования выполнялись согласно международным этическим нормам Европейской конвенции защиты позвоночных животных для экспериментальных и других научных целей (Страсбург, 1986) и „International Guiding principles for Biomedical Research Involving Animals“ (2012), а также в соответствии с рекомендациями комитета по этике Саратовского ГМУ им. В.И. Разумовского (протокол № 6 от 06.02.2018 г.).

Для перорального введения использовали покрытые полиэтиленгликолем ЗНЧ диаметром 2, 15 и $50 \mathrm{~nm}$ (концентрация золота $57 \mu \mathrm{g} / \mathrm{mL}$ ), синтезированные в лаборатории нанобиотехнологии ИБФРМ РАН (Саратов). Выбор размеров и дозировок ЗНЧ, а также внутренних органов для морфологического исследования был сделан на основании литературных данных [15] и ранее проведенных нами исследований по определению токсичности ЗНЧ при внутривенном, однократном и многократном пероральном введении $[9,10,16,17]$.

Эксперимент был разделен на три серии: первая серия была посвящена изучению морфологических изменений в печени, селезенке и лимфатических узлах лабораторных крыс при длительном пероральном введении ЗНЧ различных размеров, вторая и третья - изучению пренатального и перинатального влияния ЗНЧ на потомство.

В каждой серии эксперимента лабораторные крысы были распределены на 4 опытные группы, введение ЗНЧ осуществляли перорально в дозировке из расчета $190 \mu \mathrm{g} / \mathrm{kg}$ массы животного. Крысам опытных групп первой серии эксперимента ЗНЧ вводили через сутки в течение 30 дней: первая опытная группа - 2nm-3НЧ, вторая - 15nm-3НЧ, третья - 50nm-3НЧ. Во второй серии эксперимента ЗНЧ вводили беременным самкам в течение 10 дней, начиная с 15 дня беременности. В третьей серии эксперимента ЗНЧ вводили самкам опытных групп в период наиболее активной лактации с первого по десятый день от момента рождения потомства. К каждой серии эксперимента были сформированы контрольные группы, животным которых перорально вводили физиологический раствор в объеме $1 \mathrm{ml}$ по соответствующим схемам. Для определения даты начала беременности у самок в вагинальных мазках определяли эстральный цикл. В стадию проэструса самок подсаживали в клетку к самцу. Обнаружение сперматозоидов в вагинальных мазках расценивалось как первый день начала беременности.

Внутренние органы крыс (печень, селезенка, лимфатические узлы) фиксировали в 10\%-растворе забуференного формалина, подвергали стандартной спиртовой проводке и окрашивали гематоксилином и эозином. Для выявления гранул пигмента гемосидерина использовали реакцию Перлса. Конгломераты ЗНЧ в исследуемых органах выявляли с помощью метода микроскопии темного поля с использованием микроскопа Leica DM 2500 со специальной приставкой, позволяющей осуществлять боковое освещение при 400-кратном увеличении. Для морфометрического исследования печени, селезенки и лимфатических узлов использовали систему анализа цифровых изображений Микровизора медицинского $\mu$ Vizo-103 ЛОМО. Оценивали пролиферативную активность гепатоцитов с помощью иммуногистохимического окрашивания печени с использованием антител к Кi67 (Abcam, UK). Подсчет количества окрашенных клеток проводили по системе Histochemical score.

Статистическую обработку полученных данных выполняли с помощью пакета статистических программ SSPS-13.0. Для проверки нормальности распределения значений в выборке использовали тест Шапиро-Уилка. При отличии распределения от нормального вычисляли медиану и квартили, показатель достоверности различий $(P)$ определяли с использованием непараметрического критерия Манна-Уитни.

\section{Результаты исследования}

Проведенные исследования показали, что морфологические изменения, возникающие в печени, селезенке и лимфатических узлах у половозрелых животных (первая серия эксперимента) носят размерзависимый характер.

При морфологическом исследовании печени половозрелых крыс наиболее значимые морфологические изменения были обнаружены в опытных группах с введением ЗНЧ размером 2 и $50 \mathrm{~nm}$ : отсутствовало балочное строение, отмечались признаки повреждения паренхимы - выраженная дистрофия гепатоцитов с участками фокального некроза, выраженное полнокровие и отек стромы (рис. 1, 2). В группе введения ЗНЧ размером $15 \mathrm{~nm}$ наблюдалась умеренная дистрофия гепатоцитов и незначительное полнокровие органа. Для более детальной оценки морфологических изменений в печени было проведено морфометрическое исследование с определением следующих параметров: количество гепатоцитов с дистрофическими изменениями, количество гепатоцитов в состоянии некроза, коэффициент нормализации паренхимы (КНП), количество непаренхиматозных элементов печени (НПЭ), число двуядерных гепатоцитов. Результаты морфометрического исследования печени половозре- 
Таблица 1. Результаты морфометрического исследования печени половозрелых лабораторных крыс при пероральном введении ЗНЧ различного размера

\begin{tabular}{c|c|c|c|c}
\hline \multicolumn{2}{c|}{ Исследуемые показатели в поле зрения $(\times 400)$} & \multicolumn{4}{|c}{ Группы наблюдения } \\
\cline { 2 - 5 } & Контроль & 3 НЧ $2 \mathrm{~nm}$ & 3 ЗН $15 \mathrm{~nm}$ & 3 ЗНЧ $50 \mathrm{~nm}$ \\
\hline Количество гепатоцитов с дистрофическими изменениями & $36[30,43]$ & $167[154,178]^{*}$ & $149[138,159]^{*}$ & $205[190,220]^{*, * *, * * *}$ \\
\hline Количество гепатоцитов в состоянии некроза & $8[6,10]$ & $79[71,88]^{*}$ & $60[51,69]^{*, * *}$ & $97[88,105]^{*, * * *}$ \\
\hline КНП & 4.5 & $2.11^{*}$ & $2.5^{*}$ & $2.11^{*}$ \\
\hline Количество НПЭ печени & $7[5,8]$ & $65[48,62]^{*}$ & $59[44,74]^{*}$ & $65[57,73]^{*}$ \\
\hline Количество двуядерных гепатоцитов & $5[3,6]$ & $5[4,6]$ & $7[5,9]$ & $6[4,8]$
\end{tabular}

Примечание. ${ }^{*}$ достоверность различий с группой контроля $(P<0.001),{ }^{* *}$ достоверность различий опытной группы с группой 3 НЧ $2 \mathrm{~nm}$ $(P<0.05),{ }^{* * *}$ достоверность различий опытной группы с группой ЗНЧ $15 \mathrm{~nm}(P<0.05)$.

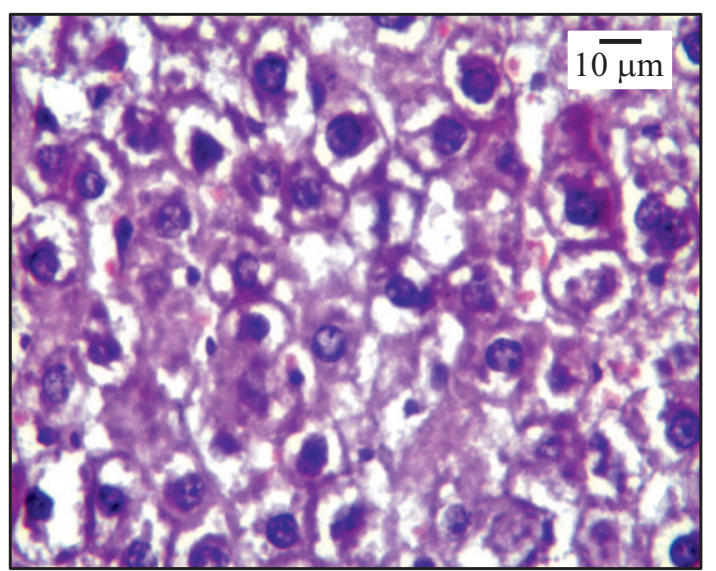

Рис. 1. Морфологическая картина печени на фоне длительного перорального введения ЗНЧ размером $2 \mathrm{~nm}$. Окрашивание гематоксилином и эозином, увеличение 774.

лых крыс первой серии эксперимента представлены в табл. 1.

В результате морфометрического исследования установлено увеличение количества гепатоцитов с дистрофическими изменениями и в состоянии некроза. Максимальное количество гепатоцитов с дистрофическими изменениями 205[190;220] и в состоянии некроза 97[88;105] обнаружено в группе введения ЗНЧ размером $50 \mathrm{~nm}$, минимальные значения - в группе введения ЗНЧ размером $15 \mathrm{~nm}(149[138 ; 159]$ и $60[51 ; 69]$ соответственно). Повышение числа гепатоцитов в состоянии дистрофии и некроза приводило к снижению КНП во всех опытных группах. Минимальные значения данного показателя $(2,11)$ получены в группах введения ЗНЧ размерами 2 и $50 \mathrm{~nm}$. Подсчет КНП позволяет оценить степень выраженности некробиотических изменений в печени и вычисляется как отношение количества гепатоцитов с дистрофическими изменениями к гепатоцитам в состоянии некроза на поле зрения. Выполненные нами ранее исследования подтвердили значимость данного параметра для определения степени повреждения паренхимы печени при воздействии наночастиц [10].

Влияние ЗНЧ разного размера на макрофагальную и лимфоцитарную системы печени оценивали подсчетом количества НПЭ (лимфоцитов, клеток Купфера, клеток Ито) в поле зрения $(\times 400)$. Во всех опытных группах количество НПЭ печени в 10 раз превышало контрольные значения, что свидетельствует об активации моноцитарно-макрофагальной системы.

Иммуногистохимическая реакция с маркером Кi67 была положительная во всех опытных группах первой серии эксперимента. Среднее значение гистосчета превышало показатели контрольной группы в 30 раз: при введении ЗНЧ размером 2 nm составило - 144[132;156], ЗНЧ размером $15 \mathrm{~nm}$ - 141[130;152], ЗНЧ размером $50 \mathrm{~nm}$ - 150[137;163]. Полученные данные свидетельствуют о высокой пролиферации гепатоцитов в ответ на длительное введение ЗНЧ.

Следует отметить, что ни в одном случае исследования в первой серии эксперимента мы не увидели скоплений гранул ЗНЧ в ткани печени ни при световой микроскопии, ни при микроскопии методом темного по-

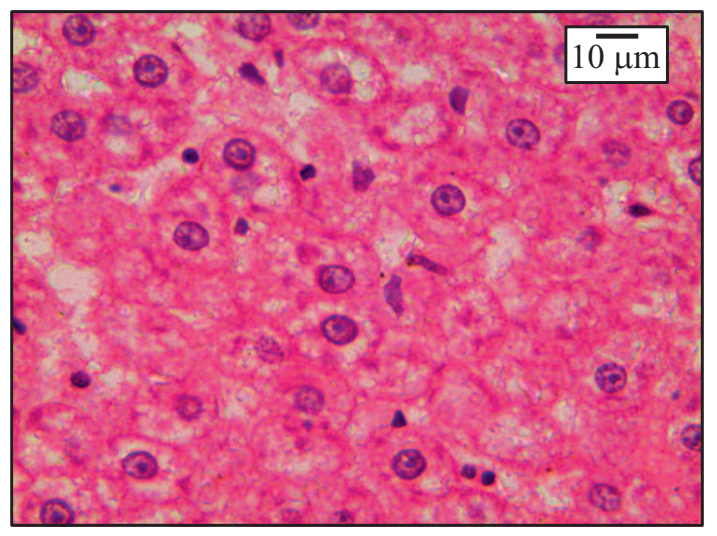

Рис. 2. Морфологическая картина печени на фоне длительного перорального введения ЗНЧ размером $50 \mathrm{~nm}$. Окрашивание гематоксилином и эозином, увеличение 774. 


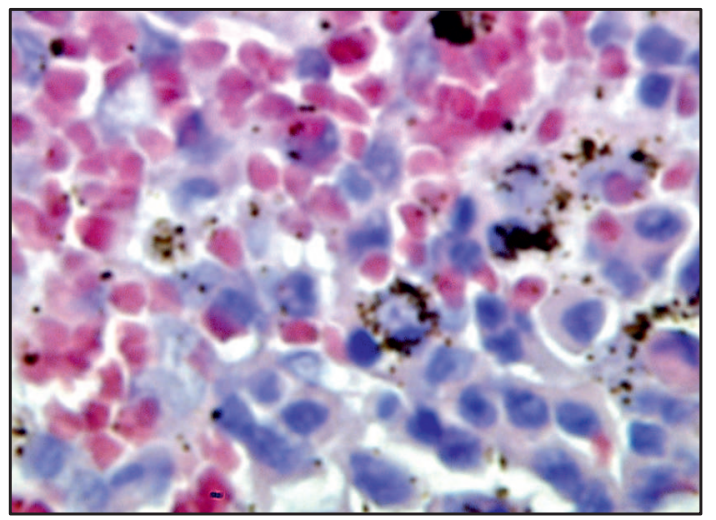

Рис. 3. Конгломераты ЗНЧ размером $15 \mathrm{~nm}$ в ткани селезенки. Окрашивание гематоксилином и эозином, увеличение 630.

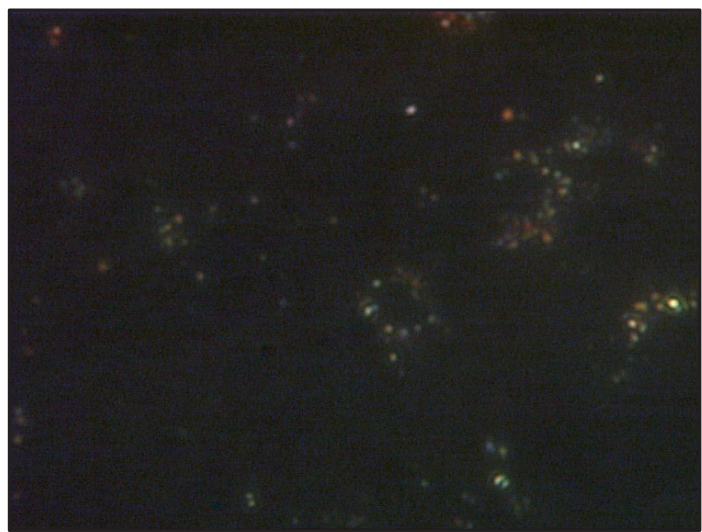

Рис. 4. Конгломераты ЗНЧ размером $15 \mathrm{~nm}$ в ткани селезенки. Микроскопия темного поля. Окрашивание гематоксилином и эозином, увеличение 630 .

ля, а лишь отмечали косвенные признаки их присутствия в организме половозрелых крыс, представленные повреждением паренхимы печени и активацией моноцитарномакрофагальной системы.

В селезенке во всех опытных группах первой серии эксперимента граница между красной и белой пульпой отчетливо не различалась. В белой пульпе размеры лимфоидных фолликулов были увеличены, в них появлялись светлые центры размножения с крупными бластными клетками. В красной пульпе во всех опытных группах были обнаружены гранулы черного цвета (рис. 3, 4). При реакции Перлса в группах введения ЗНЧ размерами 15 и $50 \mathrm{~nm}$ часть гранул окрашивалась в голубой цвет пигмент гемосидерин, часть оставалась черными конгломераты ЗНЧ, которые светились красным цветом при микроскопии методом темного поля (рис. 5,6).

В мезентериальных лимфатических узлах изменения клеточного состава отмечались во всех опытных группах. В группах введения ЗНЧ размерами 2 и $50 \mathrm{~nm}$ изменения были найдены во всех функциональных зонах органа: в корковом веществе отмечалось увеличение лимфоидных фолликулов с центром размножения, пред- ставленного иммунобластами, макрофагами и фигурами митоза, в мозговом веществе - увеличение количества плазмоцитов в мозговых тяжах, а также расширение паракортикальной зоны. В группе введения ЗНЧ размером $15 \mathrm{~nm}$ в паракортикальной зоне были найдены изменения более выраженные, чем в зонах лимфоидных фолликулов и мозговых тяжей.

Исследование лимфатических узлов с помощью микроскопии методом темного поля выявило скопления конгломератов ЗНЧ размерами 15 и $50 \mathrm{~nm}$ в мозговых синусах, в цитоплазме макрофагов и лимфоцитов мантийной зоны лимфоидных фолликулов и мозговых тяжах (рис. 7,8$)$. Необходимо подчеркнуть, что ЗНЧ размером $2 \mathrm{~nm}$ не визуализировались доступными методами ни в одной из зон лимфатических узлов.

При исследовании потомства самок, получавших ЗНЧ во время беременности и лактации, в ходе второй и третьей серий эксперимента установлено, что во всех опытных группах потомство появилось в срок, без визуальных признаков нарушения развития, среднее число особей в помете - 8, гибели новорожденных не наблюдалось. При наблюдении за потомством с 1-го по

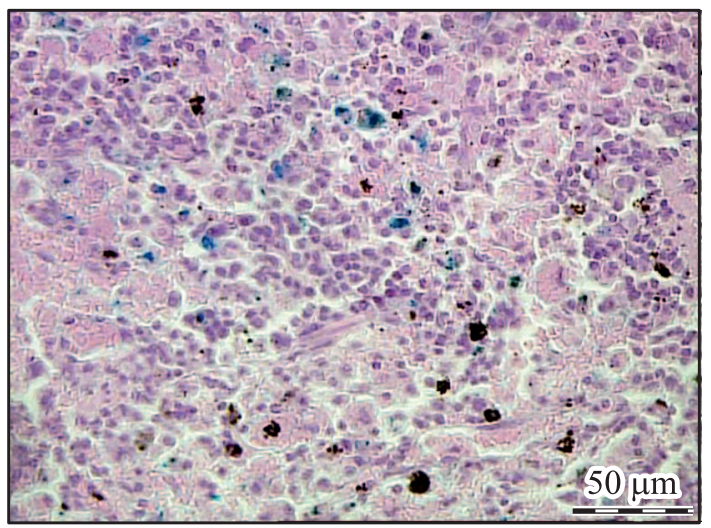

Рис. 5. Два типа частиц в ткани селезенки: голубые - гранулы гемосидерина, черные - конгломераты ЗНЧ размером $50 \mathrm{~nm}$. Окрашивание по Перлсу, увеличение 630.

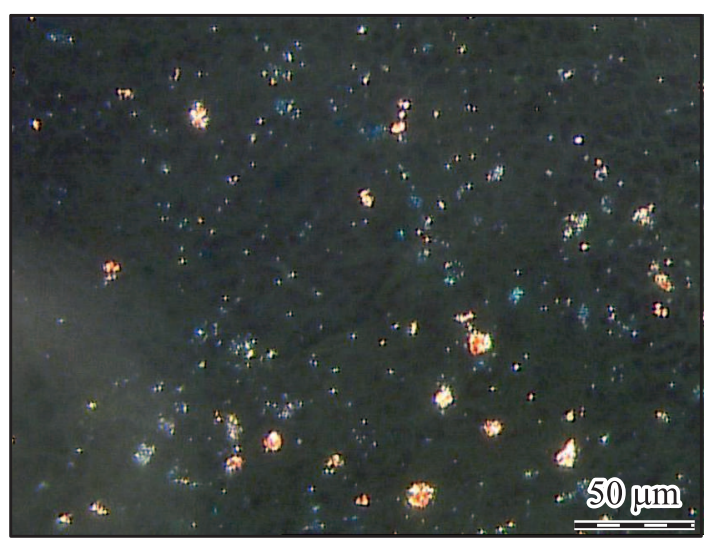

Рис. 6. Свечение конгломератов ЗНЧ за счет интенсивного рассеяния света. Микроскопия темного поля. Окрашивание по Перлсу, увеличение 630. 
Таблица 2. Результаты морфометрического исследования печени потомства лабораторных крыс при пренатальном режиме введения ЗНЧ различного размера

\begin{tabular}{c|c|c|c|c}
\hline \multicolumn{2}{c|}{ Исследуемые показатели в поле зрения $(\times 774)$} & \multicolumn{3}{|c}{ Группы наблюдения } \\
\cline { 2 - 5 } & Контроль & 3 ЗНЧ $2 \mathrm{~nm}$ & 3 ЗН $15 \mathrm{~nm}$ & 3 НЧ $50 \mathrm{~nm}$ \\
\hline Количество гепатоцитов с дистрофическими изменениями & $42[40,45]$ & $40[37,42]$ & $48[40,51]^{*}$ & $37[31,45]$ \\
\hline Количество гепатоцитов в состоянии некроза & $10[48,54]$ & $15[12,19]^{*}$ & $22[18,22]^{*}$ & $25[21,29]^{*, * *}$ \\
\hline КНП & 4.2 & $2.6^{*}$ & $2.18^{*}$ & $1.48^{*, * *}$ \\
\hline Количество НПЭ печени & $4[2,5]$ & $9[8,10]^{*}$ & $6[3,8]$ & $15[12,18]^{* * * *, * * *}$ \\
\hline Количество двуядерных гепатоцитов & $3[2,5]$ & $4[3,5]$ & $2[2,4]$ & $1[1,2]$
\end{tabular}

Примечание. ${ }^{*}$ достоверность различий с группой контроля $(P<0.001),{ }^{* *}$ достоверность различий опытной группы с группой 3 НЧ 2 nm $(P<0.001),{ }^{* * *}$ достоверность различий опытной группы с группой ЗНЧ $15 \mathrm{~nm}(P<0.001)$.

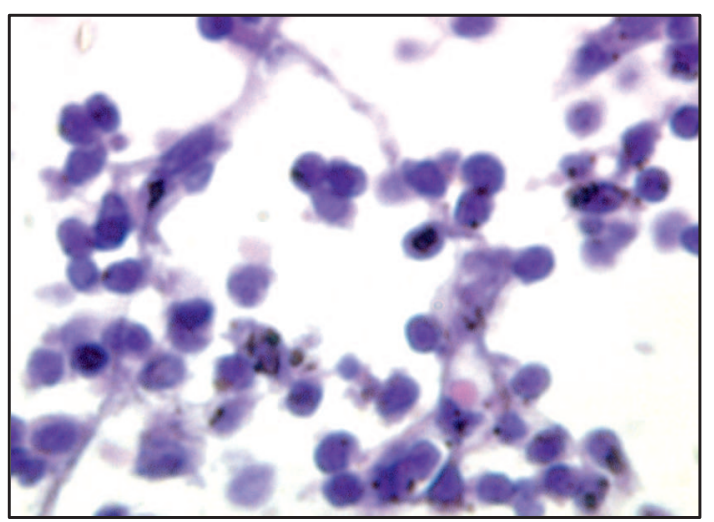

Рис. 7. Конгломераты ЗНЧ размером $50 \mathrm{~nm}$ в цитоплазме макрофагов. Окрашивание гематоксилином и эозином, увеличение 1500 .

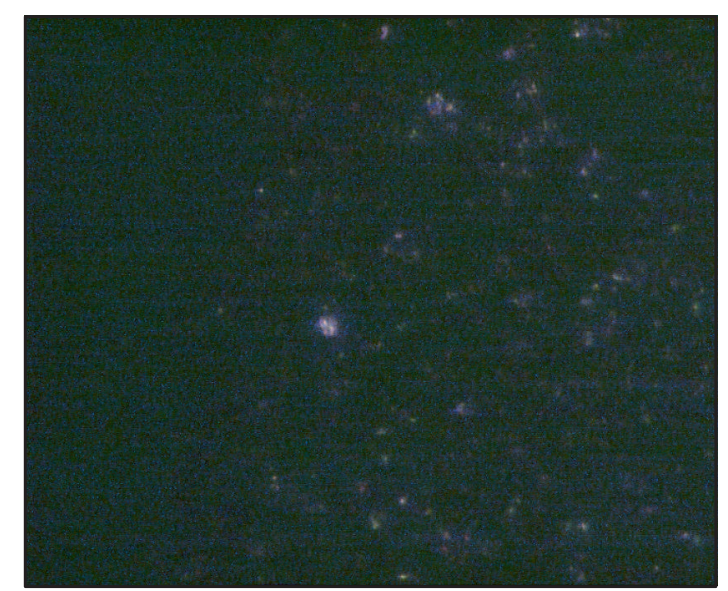

Рис. 8. Свечение конгломератов ЗНЧ за счет интенсивного рассеяния света. Микроскопия темного поля. Окрашивание гематоксилином и эозином, увеличение 1500.

120-й день жизни во всех опытных группах отмечалось нормальное физическое развитие: на 2-е сутки после рождения происходило отлипание ушной раковины, на 5-е - появление первичного волосяного покрова, на 14-е - открытие глаз. Взвешивание с 1-х по 60-е сутки жизни потомства показало, что в опытных группах второй серии эксперимента к 60-м суткам наблюдается задержка в приросте массы тела более чем на 30\% у потомства самок, получавших ЗНЧ размерами 2 и $15 \mathrm{~nm}$ во время беременности, по сравнению с группой контроля (рис. 9).

При морфологическом исследовании печени потомства во всех опытных группах второй серии эксперимента наблюдались незначительное полнокровие и умеренно выраженные дистрофические изменения гепатоцитов. При морфометрическом исследовании отмечалось увеличение количества гепатоцитов в состоянии некроза и, как следствие, повышение КНП. Наибольшее количество гепатоцитов в состоянии некроза было получено в группе введения ЗНЧ размером $50 \mathrm{~nm}-25[21 ; 29]$, что в 2.5 раза превышает показатели в контрольной группе (табл. 2). Пероральное введение ЗНЧ во время беременности самкам сопровождалось увеличением числа НПЭ печени, наиболее выраженное в группах введения ЗНЧ размерами 2 и $50 \mathrm{~nm}$.

В селезенке во всех опытных группах второй серии эксперимента граница между красной и белой пульпой различалась отчетливо, в белой пульпе размеры лимфатических фолликулов были увеличены, в них отмечались светлые центры размножения с бластными клетками.

При морфологическом исследовании печени потомства во всех опытных группах третьей серии эксперимента наблюдались нормальное кровенаполнение органа и незначительные дистрофические изменения гепатоцитов. Подсчет морфометрических показателей не выявил достоверных различий между опытными и контрольными группами.

В селезенке во всех опытных группах третьей серии эксперимента граница между красной и белой пульпой различалась отчетливо. В белой пульпе - лимфоидные фолликулы имели обычный размер, были округлой или овальной формы. В единичных фолликулах отмечались 


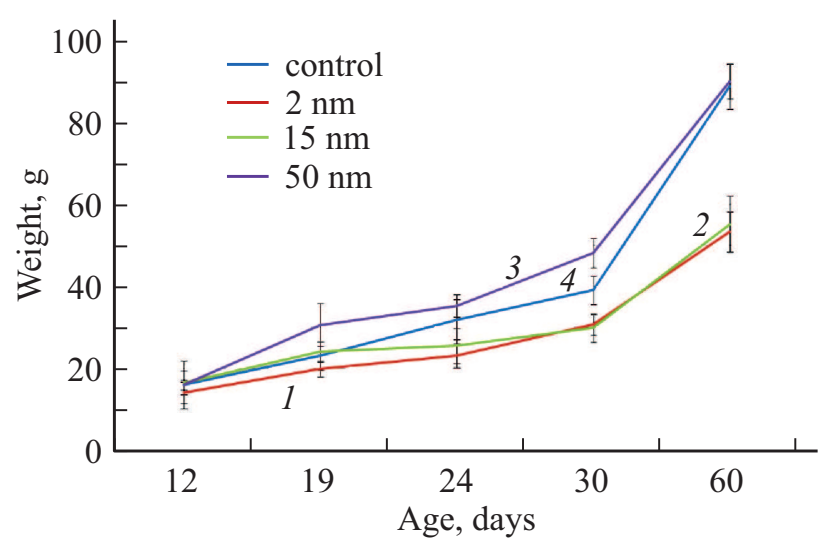

Рис. 9. Динамика массы тела потомства лабораторных крыс при пренатальном режиме введения ЗНЧ различного размера: 2 (1), 15 (2), $50 \mathrm{~nm} \mathrm{(3);} 4$ - контроль.

светлые центры размножения, содержащие бластные клетки.

Следует отметить, что во второй и третьей сериях эксперимента в ткани печени и селезенки потомства мы не зафиксировали скопления конгломератов ЗНЧ ни в одном случае исследования ни при использовании световой микроскопии, ни при микроскопии методом темного поля.

\section{Выводы}

Степень выраженности морфологических изменений в печени, селезенке и лимфатических узлах при длительном пероральном введении ЗНЧ у половозрелых крыс носит размерзависимый характер. Наиболее выраженные дистрофические изменения в печени, а также активация моноцитарно-макрофагальной системы наблюдались в группе с пероральным введением ЗНЧ размером $50 \mathrm{~nm}$. В селезенке и лимфатических узлах происходила активация процессов пролиферации и дифференцировки иммунокомпетентных клеток и макрофагов.

В печени потомства самок, получавших перорально ЗНЧ во время беременности, наблюдалось увеличение количества гепатоцитов с некробиотическими изменениями, наиболее выраженное в группе с введением ЗНЧ размером $50 \mathrm{~nm}$. Пероральное ведение ЗНЧ во время беременности самкам сопровождалось увеличением числа непаренхиматозных элементов в печени у потомства, наиболее выраженным в группах с введением ЗНЧ размером 2 и $50 \mathrm{~nm}$. При пероральном введении ЗНЧ самкам во время лактации значимых морфологических изменений во внутренних органах потомства не было выявлено.

Полученные результаты позволяют рекомендовать для дальнейших исследований с использованием беременных и кормящих лабораторных животных ЗНЧ размером $15 \mathrm{~nm}$ как наименее токсичные и наиболее безопасные для потомства.

\section{Финансирование работы}

Исследование проведено на базе Центра коллективного пользования ФГБОУ ВО Саратовского ГМУ им. В.И. Разумовского Минздрава России в рамках государственного задания Минздрава России „Молекулярные маркеры и золотые наночастицы: применение для целей тераностики в экспериментальной и клинической онкологии“. Работа по синтезу наночастиц поддержана грантами РФФИ 17-02-00075 и 18-52-7803.

\section{Соблюдение этических стандартов}

Все применимые международные, национальные и/или институциональные принципы ухода и использования животных были соблюдены.

\section{Конфликт интересов}

Авторы заявляют об отсутствии явных и потенциальных конфликтов интересов, связанных с настоящей статьей.

\section{Список литературы}

[1] Nie S., Xing Y., Kim G.J., Simons J.W. // Ann. Rev. Biomed. Eng. 2007. V. 9. P. 12.1-12.32.

[2] De Mrinmoy, Ghosh P.S., Rotello V.M. // Adv. Mater. 2008. V. 20. P. 4225.

[3] Veiseh O., Tang B.C., Whitehead K.A., Anderson D.G., Langer R. // Nat. Rev. Drug Discov, 2015. V. 14. N 1. P. $45-57$.

[4] Dykman L.A., Khlebtsov N.G. // Biochemistry (Moscow). 2016. V. 81. N 13. P. $1771-1789$. doi $10.1134 / \mathrm{S} 0006297916130125$

[5] Venkatachalam M., Govindaraju K., Mohamed S.A., Tamilselvan S., Ganesh K.V., Singaravelu G. // Spectrochim. Acta. A. 2013. V. 116. P. 331-338.

[6] Bucharskaya A., Maslyakova G., Terentyuk G., Yakunin A., Avetisyan Y., Bibikova O., Tuchina E., Khlebtsov B., Khlebtsov N., Tuchin V. // Int. J. Mol. Sci. 2016. V. 17. N 8. P. 1295. doi org/10.3390/ijms17081295

[7] Stewart M.E., Anderton R., Thompson L.B., Maria J., Gray S.K, Rogers J.A., Nuzzo R.G. // Chem. Rev. 2008. N 108 (2). P. 494-521.

[8] Park J., Estrada A., Sharp K., Sang K., Schwartz J.A., Smith D.K., Coleman C., Payne J.D., Korgel B.A., Dunn A.K., Tunnell J.W. // Opt. Expr. 2008. N 16. P. 1590-1599.

[9] Злобина О.В., Пахомий С.С., Бучарская А.Б., Бугаева И.О., Маслякова Г.Н., Хлебцов Н.Г., Хлебцов Б.Н., Богатырев B.A. // Саратовский научно-медицинский журнал. 2013. T. 9. № 1. С. 17-20.

[10] Маслякова Г.Н., Пахомий С.С., Бучарская А.Б., Злобина О.В., Наволокин Н.А., Понукалин А.Н., Хлебцов Н.Г., Хлебцов Б.Н., Богатырев В.А. // Саратовский научномедицинский журнал. 2013. Т. 9. № 2. С. 208-213.

[11] Цыганова Н.А., Хайруллин Р.М., Терентюк Г.С., Дрожсдина Е.П., Баско М.В., Хлебцов Н.Г., Гальчин А.В. // Фундаментальные исследования. 2013. Т. 4. С. 394-397. 
[12] Wick P., Malek A., Manser P., Meili D., MaederAlthaus X., Diener L., Diener P.-A., Zisch A., Krug H.F., von Mandach U. // Environ. Health Perspect. 2010. V. 118. P. 432.

[13] Myllynen P.K., Loughran M.J., Howard C.V. // Reprod. Toxicol. 2008. V. 26. P. 130-137.

[14] Schleh C., Semmler-Behnke M., Lipka J., Wenk A., Hirn S., Schäffler M., Schmid G., Simon U., Kreyling W.G. // Nanotoxicology. 2012. V. 6. P. 36-46.

[15] Khlebtsov N.G., Dykman L.A. // Chem. Soc. Rev. 2011. V. 40. P. $1647-1671$.

[16] Jumagazieva D.S., Maslyakova G.N., Suleymanova L.V., Bucharskaya A.B., Firsova S.S., Terentyuk G.S., Kong S.M., Khlebtsov B.N., Khlebtsov N.G. // Bull. Exp. Biol. Med. 2011. V. 151. N 6. P. $731-733$.

[17] Zlobina O.V., Bugaeva I.O., Maslyakova G.N., Firsova S.S., Bucharskaya A.B., Khlebtsov N.G., Khlebtsov B.N., Dykman L.A. // Russ. Open Med. J. 2012. V. 1. N 3. P. 0302. 